\title{
Komunikasi Pemasaran Kennedy, Voice \& Berliner dalam Membangun Loyalitas dengan Klien
}

\author{
Jacqueline Annabell, Yugih Setyanto, Sisca Aulia \\ Jacquelineannabell28@gmail.com,yugihs@fikom.untar.ac.id,siscaa@fikom.untar.ac.id
}

Fakultas Ilmu Komunikasi Universitas Tarumanagara

\begin{abstract}
Marketing communication is carried out with the main goal of selling. Companies that offer services and products compete with each other in applying marketing communication strategies to attract clients and maintain the loyalty of clients who have become regular customers. This research utilizes marketing communication theory and client's loyalty. The research approach used in this research is a descriptive qualitative approach with case study research methods and data collection techniques carried out by interviews, non-participant observation, literature study and documentation. The result of this study indicates that Kennedy, Voice \& Berliner runs a mix of marketing communications, namely events and experiences, public relations and publicity, direct marketing, word-of-mouth marketing, and personal selling. Kennedy, Voice \& Berliner clients have a high level of engagement and are supported by a high level of repeated purchase, reciprocity and client's satisfaction with Kennedy, Voice \& Berliner in which they use the services of Kennedy, Voice \& Berliner's public relations consultant on an ongoing basis.
\end{abstract}

Keywords: clients, kennedy, voice \& berliner, marketing communication, loyalty,

\begin{abstract}
Abstrak
Komunikasi pemasaran dilaksanakan dengan tujuan utama menjual. Perusahaan-perusahaan yang menawarkan jasa maupun produk saling berkompetisi dalam mengaplikasikan strategi komunikasi pemasaran untuk menarik minat klien serta mempertahankan loyalitas klien yang telah menjadi pelanggan tetap. Penelitian ini menggunakan teori komunikasi pemasaran dan loyalitas klien. Pendekatan penelitian yang digunakan dalam penelitian ini adalah pendekatan kualitatif deskriptif dengan metode penelitian studi kasus dan teknik pengumpulan data dilakukan dengan wawancara, observasi non-participant, studi pustaka dan dokumentasi. Hasil penelitian ini menunjukan bahwa Kennedy, Voice \& Berliner menjalankan bauran komunikasi pemasaran yaitu events and experiences, public relations and publicity, direct marketing, word-of-mouth marketing, dan personal selling. Klien Kennedy, Voice \& Berliner memiliki keterikatan yang tinggi dan didukung dengan tingkat pembelian ulang yang tinggi, adanya timbal balik dan rasa puas klien terhadap Kennedy, Voice \& Berliner sehingga memakai jasa konsultan public relations Kennedy, Voice \& Berliner secara terus-menerus.
\end{abstract}

Kata Kunci: kennedy voice \& berliner, klien, komunikasi pemasaran, loyalitas,

\section{Pendahuluan}

Perkembangan pesat dalam bisnis disertai dengan adanya kompetisi yang semakin tinggi dalam menguasai pasar, membuat perusahaan bersama-sama memperluas kreativitasnya, terlebih kreativitas public relations dalam melakukan aktivitas komunikasi untuk menarik minat masyarakat dan yang terutama ialah untuk membangun citra perusahaan dan mempertahankan klien yang loyal. Oleh sebab itu, 
dibutuhkan strategi khusus yang digunakan untuk mendapatkan loyalitas dan minat klien, yaitu dengan mengaplikasikan strategi komunikasi pemasaran.

Strategi komunikasi pemasaran adalah strategi yang dilakukan oleh public relations dengan pendekatan dalam memberikan pesan mengenai jasa atau produk perusahaan yang dipromosikan kepada klien. Komunikasi pemasaran dilaksanakan dengan maksud untuk menjual. Perusahaan yang mempromosikan jasa atau produk saling berkompetisi dalam mengaplikasikan strategi komunikasi pemasaran agar klien merasa tertarik serta mempertahankan loyalitas klien yang telah menjadi pelanggan tetap.

Dalam mempertahankan klien, sebuah perusahaan harus memiliki strategi komunikasi pemasaran yang baik dalam menjalankan tugas yang diminta oleh klien tersebut agar klien dapat memperoleh kepuasan yang merupakan penghargaan tertinggi bagi suatu perusahaan. Loyalitas klien merupakan sesuatu yang penting untuk memiliki hubungan yang baik dengan perusahaan. Klien akan memiliki rasa loyalitas jika melihat perusahaan sebagai perusahaan yang baik. Berdasarkan latar belakang yang dikemukakan diatas, maka penulis ingin melakukan penelitian dengan judul penelitian "Komunikasi Pemasaran Kennedy, Voice \& Berliner dalam Membagun Loyalitas dengan Klien."

\section{Komunikasi Pemasaran}

Komunikasi pemasaran (Kotler dan Keller, 2009) adalah media yang digunakan oleh perusahaan untuk memberikan informasi, mengingatkan, membujuk klien dengan cara langsung atau tidak secara langsung tentang merek, produk, atau jasa yang ditawarkan. Komunikasi pemasaran dapat menjadi petunjuk mengenai mengapa dan bagaimana produk/jasa tersebut yang dipakai, dengan siapa, dimana, dan kapan. Komunikasi pemasaran menjadi jembatan penghubung antara perusahaan dengan tempat, manusia, pengalaman, perasaan, dan acara. Perusahaan memiliki kontribusi untuk mengingatkan merek terhadap konsumen dan mempertahankan citra perusahaan, serta meningkatkan penjualan, dan mempengaruhi nilai saham.

Marketing communication, juga merupakan bentuk komunikasi yang bertujuan untuk memperkuat strategi pemasaran, guna meraih segmentasi yang lebih luas. Kajian ini dapat juga dikatakan sebagai upaya untuk memperkuat loyalitas pelanggan terhadap produk, yaitu barang dan jasa yang dimiliki perusahaan. Hal yang perlu dipahami oleh seorang pemasar adalah keberhasilan sebuah strategi marketing communication dapat diukur dengan seberapa besar penjualan sebuah produk atau penghasilan dari pemanfaatan jasa oleh konsumen. (Kusniadji, 2016).

\section{Bauran Promosi}

Dalam pemasaran, menurut Kotler dan Keller (2014), terdapat delapan bauran promosi yaitu :

1. Advertising

Segala bentuk penyampaian secara nonpersonal, promosi barang / jasa yang menggunakan media yang berbayar.

2. Sales promotion

Suatu aktivitas pemasaran yang berupaya menciptakan peningkatan kegiatan pembelian suatu produk yang cepat dengan kegiatan tertentu. 


\section{Events and experiences}

Suatu cara yang dilakukan perusahaan untuk melakukan promosi mengenai perusahaan dan brand dengan menginterpretasikan perusahaan dengan mengadakan kegiatan atau acara tertentu.

4. Public relations and publicity

Publicity mendeskripsikan komunikasi secara promosional mengenai produk atau jasa yang ditawarkan perusahaan melalui media, tetapi tidak ada biaya yang dikeluarkan oleh perusahaan untuk beriklan.

\section{Direct marketing}

Penggunaan email, internet, telepon, surat, untuk melakukan komunikasi secara langsung kepada konsumen.

6. Interactive marketing

Program yang dirancang untuk menciptakan hubungan yang baik dengan klien dengan cara langsung atau tidak langsung agar meningkatkan pembelian dan pelayanan.

7. Word-of-mouth marketing

Pertemuan secara langsung, tidak langsung, tertulis dan media elektronik antar individu, yang dapat memperluas pengalaman dalam pembelian barang dan jasa.

8. Personal selling

Serangkaian komunikasi antar individu saat perusahaan memberikan informasi, mengingatkan, dan membujuk calon klien untuk melakukan pembelian produk atau jasa yang ditawarkan oleh perusahaan.

\section{Jenis Loyalitas}

Menurut Jill Griffin (2005) terdapat empat jenis loyalitas, yaitu :

1. Tanpa Loyalitas

Karena beberapa alasan tertentu, ada klien yang tidak mempertahankan kesetiaan atau loyalitas kepada suatu produk maupun jasa tertentu. Tingkat keterikatan yang rendah dengan tingkat pembelian ulang yang rendah menunjukkan tidak adanya suatu loyalitas. Pada dasarnya, suatu perusahaan harus menghindari konsumen/klien tanpa loyalitas ini untuk dijadikan target pasar, karena mereka tidak akan menjadi konsumen yang loyal.

2. Loyalitas yang lemah (Inertia loyalty)

Loyalitas yang lemah ialah jenis loyalitas konsumen yang memiliki rasa keterikatan yang rendah dengan pembelian ulang yang tinggi. Konsumen yang mempunyai sikap ini biasanya membeli karena adanya suatu kebiasaan. Dasar yang digunakan untuk pembelian produk atau jasa disebabkan oleh faktor kemudahan situasional.

3. Loyalitas Tersembunyi (Laten loyalty)

Loyalitas tersembunyi yaitu adanya keterikatan yang relatif tinggi diikuti dengan adanya pembelian ulang yang tidak maksimal. Konsumen/klien yang mempunyai sikap laten loyalty, terjadinya pembelian berkala berdasarkan pengaruh faktor situasional.

4. Loyalitas Premium (Premium Loyalty)

Loyalitas premium adalah apabila adanya kesetiaan yang memiliki keterikatan tinggi yang selaras dengan aktivitas pembelian berulang-ulang. Semua perusahaan pastinya sangat menginginkan klien atau konsumennya memiliki loyalitas premium. 


\section{Metode Penelitian}

Pendekatan penelitian yang digunakan dalam penelitian ini adalah pendekatan kualitatif deskriptif. Menurut Lexy J. Moleong (2010) metodologi kualitatif adalah penelitian untuk memahami mengenai fenomena apa yang dialami oleh subjek penelitian, misalnya persepsi, perilaku, tindakan, motivasi, secara holistik dengan mendeskripsikan dalam bentuk kata-kata dan bahasa, pada suatu konteks khusus yang alamiah dengan memanfaatkan berbagai metode ilmiah.

Format deskriptif kualitatif, biasanya dilakukan pada penelitian dalam bentuk studi kasus. Deskriptif kualitatif pada studi kasus merupakan penelitian eksplorasi dan memiliki peranan yang sangat penting dalam menciptakan pemahaman orang mengenai berbagai variabel sosial yang ada, ciri lainnya adalah memusatkan diri pada suatu unit tertentu dari berbagai fenomena (Bungin, 2011).

Metode penelitian yang digunakan dalam penelitian ini adalah studi kasus. Studi kasus berfokus pada spesifikasi kasus dalam suatu kejadian baik itu yang mencakup individu, kelompok budaya, ataupun suatu potret kehidupan. Creswell (2010: 20) mengatakan bahwa studi kasus merupakan strategi penelitian dimana peneliti menyelidiki secara cermat suatu peristiwa, aktivitas, proses, program, atau sekelompok individu. Metode yang digunakan untuk mengumpulkan data adalah wawancara, observasi non - partisipan, studi kepustakaan, dan dokumentasi. Narasumber yang diwawancarai adalah :

- Dian Noeh Abubakar, CEO Kennedy, Voice \& Berliner

- Andini Mardiani. Konsultan public relations Kennedy, Voice \& Berliner

- Nadiul Kaffi, Konsultan public relations Kennedy, Voice \& Berliner

- Wicaksono Soebroto, Head of communications PT Goodyear Indonesia

Teknik analisis data kualitatif yang digunakan peneliti untuk mengolah dan menganalisis data dalam penelitian ini, ialah menggunakan model Miles dan Huberman. Ada empat macam kegiatan dalam analisis data kualitatif, yaitu:

1. Pengumpulan data, untuk memperoleh data, peneliti melakukan wawancara dengan beberapa informan.

2. Reduksi data, merupakan proses seleksi, penyederhanaan, dan abstraksi.

3. Penyajian data, yaitu sekumpulan informasi yang tersusun sehingga memberikan kemungkinan penarikan kesimpulan dan pengambilan tindakan.

4. Penarikan kesimpulan

Teknik keabsahan data yang digunakan penulis adalah triangulasi teknik yang berarti peneliti menggunakan teknik pengumpulan data yang berbeda-beda untuk mendapatkan data dari sumber yang sama.

\section{Hasil Temuan dan Diskusi}

Hasil penelitian yang didapatkan oleh penulis adalah sebagai berikut: komunikasi pemasaran adalah cara membangun hubungan perusahaan dengan konsumen melalui pengaruh suatu perusahaan terhadap pihak lain atau target audience dalam mempertahankan hubungan bisnis dengan memanfaatkan berbagai jenis media. Strategi komunikasi pemasaran yang digunakan Kennedy, Voice \& Berliner dalam membangun loyalitas dengan Goodyear adalah dengan memberikan penghargaan kepada Goodyear sebagai pelanggan yang loyal terhadap Kennedy, Voice \& Berliner 
dengan cara menanggapi masukan, maupun memberikan hadiah berupa bauran promosi dan insentif lainnya.

Membangun kepercayaan klien bukanlah hal yang mudah karena dibutuhkannya proses yang tidak sebentar untuk klien dapat mempercayai sebuah produk/perusahaan. Dalam hal ini, Kennedy, Voice \& Berliner dapat membangun kepercayaan sehingga mendapatkan loyalitas Goodyear adalah dengan menjaga reputasi Kennedy, Voice \& Berliner itu sendiri, membuktikannya dengan tingkat profesionalitas Kennedy, Voice \& Berliner, kualitas dan mutu dari produk Kennedy, Voice \& Berliner, bersikap transparan, dan tetap berkomitmen untuk membantu Goodyear dalam memenuhi keberhasilan bisnisnya.

Alasan Goodyear untuk terus menggunakan jasa konsultan public relations Kennedy, Voice \& Berliner adalah karena Kennedy, Voice \& Berliner memberikan kesempatan kepada Goodyear untuk terhubung dengan platform kegiatan lain, biaya yang masih terjangkau (dalam proses bidding yang wajar), lebih baik menggunakan boutique agency daripada big chain company yang hanya membebankan biaya jasa lebih mahal tetapi memberikan layanan sama, serta konsultan yang membantu masih lebih mudah dihubungi dan sedia saat dibutuhkan.

Strategi komunikasi pemasaran yang digunakan Kennedy, Voice \& Berliner dalam membangun loyalitas dengan Investree adalah Kennedy, Voice \& Berliner lebih menekankan pada konsistensi dalam konten dan deliverables yang ditawarkan sehingga tidak ada kesenjangan dalam pelayanan dan deliverables yang diberikan. Serta dengan memberikan hubungan profesional terbaik, dengan cara memenuhi setiap kewajiban yang diberikan kepada Kennedy, Voice \& Berliner, dan juga menjaga hubungan interpersonal.

Menurut Jill Griffin (2005:22) terdapat empat jenis loyalitas, yaitu tanpa loyalitas, loyalitas yang lemah, loyalitas tersembunyi, dan loyalitas premium. Dian berpendapat bahwa kliennya yaitu Goodyear Indonesia, Investree, dan UBS memiliki loyalitas premium dimana adanya keterikatan yang tinggi dan didukung dengan tingkat pembelian ulang yang tinggi, adanya timbal balik dan rasa puas klien terhadap Kennedy, Voice \& Berliner sehingga memakai jasa konsultan public relations Kennedy, Voice \& Berliner secara terus-menerus. Menurut Andini, Goodyear dapat dikatakan sebagai klien yang memiliki loyalitas premium. Hal tersebut dikatakan demikian karena dalam waktu yang tidak singkat, Goodyear telah mempercayai Kennedy, Voice \& Berliner untuk membantunya berkomunikasi dengan berbagai program kerja public relations yang telah dilakukan untuk memenuhi tujuan bisnis hingga saat ini. Kaffi berpendapat bahwa Investree merupakan klien yang memiliki loyalitas tersembunyi, karena hubungan Investree dan Kennedy, Voice \& Berliner masih sangat bergantung pada kondisi yang situasional dan masih memiliki keterkaitan personal yang kuat.

Kennedy, Voice \& Berliner menjalankan bauran komunikasi pemasaran yang berfokus kepada events and experiences, public relations and publicity dikarenakan dinilai lebih efektif. Sedangkan untuk direct marketing, word-of-mouth marketing, personal selling hanya sedikit digunakan. Advertising, sales promotion, interactive marketing tidak digunakan oleh Kennedy, Voice \& Berliner karena dianggap tidak efektif.

1. Events and Experiences, dengan mengadakan dinner bersama klien atau mengadakan event yang mengundang para jurnalis dari berbagai media cetak dan online untuk datang ke acara tersebut sehingga para jurnalis akan memberikan feedback dengan cara memuat berita. 


\section{Gambar 1 Event Investree}

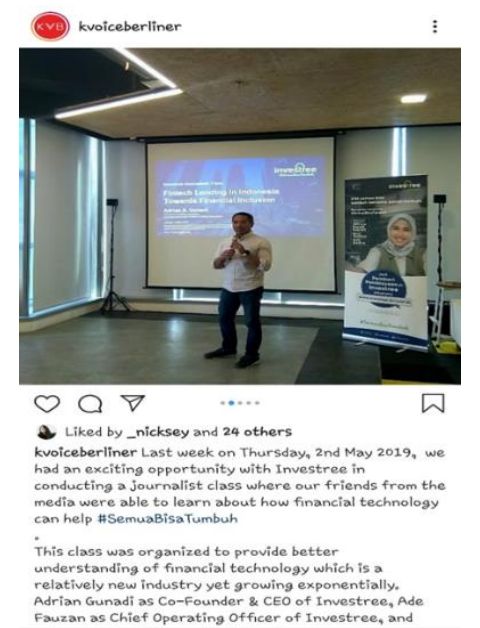

\section{Sumber : Instagram @ kvoiceberliner}

\section{Public Relations and Publicity}

Public relations ini tentu dilakukan Kennedy, Voice \& Berliner sebagai perusahaan konsultan public relations dengan tampil di banyak media terutama media online mengenai industri public relations.

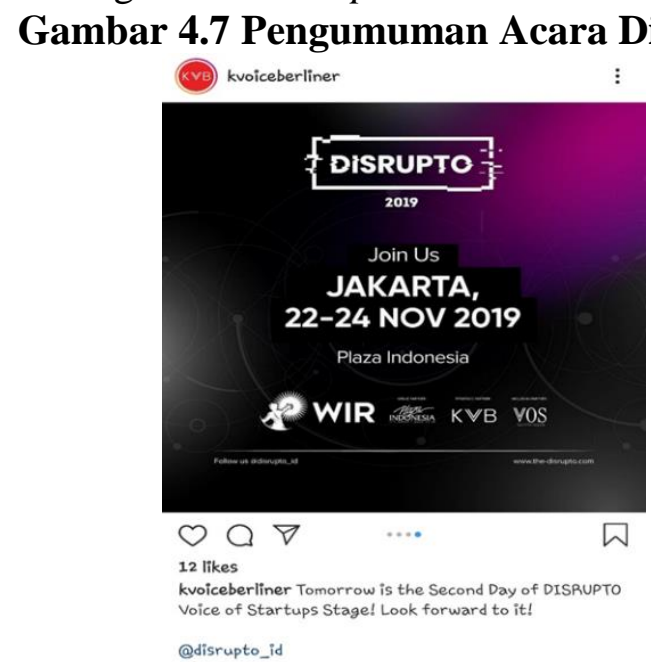

\section{Sumber : Instagram @kvoiceberliner}

Selain itu Public Relations juga dilakukan Kennedy, Voice \& Berliner melalui instagramnya, biasanya hal yang dilakukan adalah untuk memperingati hari penting dan menyampaikan suatu pesan seperti penyampaian informasi mengenai suatu event klien yang ditangani oleh Kennedy, Voice \& Berliner. Hal tersebut dilakukan untuk adanya komunikasi yang dapat membangun hubungan baik dengan klien.

Kennedy, Voice \& Berliner juga melakukan media handling, membuat press release untuk disebarkan kepada jurnalis saat sudah berlangsungnya suatu event klien, dan membantu mengatur interview.

3. Direct Marketing, dengan menggunakan email blast kepada jurnalis dalam menginformasikan suatu event yang dilakukan oleh klien serta dalam menyebarkan press release. 
4. Word-of-mouth marketing, dilakukan berdasarkan adanya referensi dari berbagai pihak mengenai jasa konsultan public relations Kennedy, Voice \& Berliner.

5. Personal Selling, dilakukan Kennedy, Voice \& Berliner untuk menaikkan personal branding nya. Dalam melakukan personal selling terdapat suatu program yaitu Kennedy, Voice \& Berliner Next Generation Leader untuk mempromosikan pegawai-pegawainya yang memiliki potensi untuk mewakili brand Kennedy, Voice \& Berliner.

Keefektifan bauran promosi dapat terlihat dari tingkat loyalitas pelanggan tersebut seperti bauran promosi yang dilakukan telah ditanggapi oleh klien dengan sangat positif. Adanya kombinasi strategi ini telah mempengaruhi tingkat kepuasan dan kepercayaan klien dalam mempertahankan loyalitas serta mengukur jumlah engagement yang dilakukan oleh klien baik dari media maupun dari consumer.

Hambatan dan tantangan dalam menjalankan komunikasi pemasaran adalah dengan adanya perbedaan tingkat pengalaman antara sesama konsultan, apakah pesan yang ingin disampaikan kepada klien dapat tersalurkan dengan baik, serta tingginya turn over rate sehingga perlu dilakukan re-brief dan re-adjustment berulang ulang demi adanya kesamaan dalam standar konten dan deliverables.

\section{Simpulan}

Klien Kennedy, Voice \& Berliner yaitu Investree, Goodyear Indonesia mempunyai tingkat pembelian ulang yang tinggi dan diikuti dengan keterikatan yang tinggi, adanya feedback dan rasa puas klien terhadap Kennedy, Voice \& Berliner sehingga memakai jasa konsultan public relations Kennedy, Voice \& Berliner secara berkala. Kennedy, Voice \& Berliner menggunakan bauran komunikasi pemasaran events and experiences, public relations and publicity, direct marketing, word-ofmouth marketing, dan personal selling. Hambatan dan tantangan dalam melakukan komunikasi pemasaran karena adanya perbedaan pengalaman antara sesama konsultan serta tingginya turn over rate sehingga perlu dilakukan re-brief dan re-adjustment demi adanya kesamaan dalam standar konten.

\section{Ucapan Terima Kasih}

Penyusunan skripsi ini dapat terlaksana karena bantuan dan dukungan dari banyak pihak. Oleh sebab itu, penulis ingin menyampaikan rasa terima kasih yang sebesar-besarnya kepada semua pihak yang ikut terlibat dan telah membantu peneliti baik secara langsung maupun tidak langsung selama proses penelitian ini berlangsung, yaitu:

1. Para narasumber yaitu Bu Dian, Kak Andini, Kak Kaffi dan Mas Wicak yang telah meluangkan waktunya untuk wawancara.

2. Orang tua dan saudara kandung yang selalu mendukung dan memberikan semangat untuk menyelesaikan skripsi ini.

3. Para Dosen dan staff Fakultas Ilmu Komunikasi yang telah membantu penulis. 


\section{Daftar Pustaka}

Asshiddiq, Nuruzzaman. (2015). Komunikasi Pemasaran dalam Meningkatkan Penjualan (Studi Deskriptif Kualitatif Pada Gudeg Kaleng Bu Tjitro Yogyakarta). Skripsi. Oktober 9, 2019. Terarsip di: http://digilib.uinsuka.ac.id/15676/

Bungin, Burhan. (2011). Penelitian Kualitatif. Jakarta: Kencana Predana Media Group.

Creswell, John W. (2010). Research Design Pendekatan Kualitatif, Kuantitatif, dan Mixed. Yogyakarta: Pustaka Pelajar.

Griffin, Jill. (2005). Customer Loyalty: Menumbuhkan \& Mempertahankan Kesetiaan Pelanggan. Jakarta : Erlangga.

Kotler, Philip \& Gerry Armstrong. (2014). Principle Of Marketing (15th ed.). New Jersey: Pearson Pretice Hall.

Kotler, Philip \& Kevin Lane Keller. (2008). Manajemen Pemasaran. Jakarta : Erlangga.

Kusniadji, Suherman. (2016). Strategi Komunikasi Pemasaran Dalam Kegiatan PemasaranProduk Consumer Goods (Studi Kasus Pada PT Expand Berlian Mulia Di Semarang). Journal Untar Vol. 8, No. 1. Terarsip di : https://journal.untar.ac.id/index.php/komunikasi/article/view/49/54

Moleong, Lexy J. (2010), Metodologi penelitian kualitatif. Bandung : Remaja Rosdakarya.

Nurwidayat, Ayu. (2015). Analisis Pengaruh Pelayanan Dan Keragaman Barang Terhadap Loyalitas Konsumen (Studi Pada Pasar Bunder Di Sragen). Skripsi. Oktober 9, 2019. Terarsip di : http://eprints.ums.ac.id/36842/ 